\title{
CONTROL DE CONSTITUCIONALIDAD Y JUSTICIA CAUTELAR EN LOS ESTADOS UNIDOS: EL CASO DE LA ORDEN EJECUTIVA SOBRE ASUNTOS DE INMIGRACIÓN DE 27 DE ENERO DE 2017
}

\author{
ALLAN R. BREWER-CARÍAS \\ Universidad Central de Venezuela \\ allanbrewercarias@gmail.com
}

Cómo citar/Citation

Brewer-Carías, A. R. (2017).

Control de constitucionalidad y justicia cautelar en los Estados Unidos: el caso de la orden ejecutiva sobre asuntos de inmigración de 27 de enero de 2017. Revista de Administración Pública, 203, 443-478. doi: https://doi.org/10.18042/cepc/rap.203.15

\section{Resumen}

Este comentario tiene por objeto analizar los razonamientos jurídicos constitucionales formulados tanto por el juez de distrito del distrito Oeste del Estado de Washington en los Estados Unidos de América como de la Corte de Apelaciones del Noveno Circuito con sede en San Francisco, en sentencias dictadas los días 3 y 9 de febrero de 2017, al decidir la demanda de inconstitucionalidad intentada por los estados de Washington y Minnesota, contra la Orden Ejecutiva dictada por el presidente Donald J. Trump, en materia de inmigración el 27 de enero de 2017, en las cuales se reafirmó el principio de la competencia de los tribunales de los Estados Unidos para ejercer el control de constitucionalidad de los actos del Poder Ejecutivo, y con base en la presunción de inconstitucionalidad de la medida, mediante una decisión de amparo cautelar suspendieron sus efectos a nivel nacional.

\section{Palabras clave}

Órdenes ejecutivas; política inmigratoria; control de constitucionalidad; medidas de amparo cautelar. 


\section{Abstract}

This comment analyzes the constitutional arguments followed by the District Court of the West District of the State of Washington in the United States, as well as by the Court of Appeal for the Ninth Circuit in decisions of February 3 and 9, 2017, resolving the claims filed by the States of Washington and Minnesota on grounds of unconstitutionality, against the Executive Order issued by President Donald J. Trump on January 27, 2017 on matters of Immigration, in which the courts reaffirmed their jurisdiction to judicial review Executive acts, and based on the presumption of unconstitutionality argued in the case, issued a Temporary Restraining Order suspending the effects of the Order with national effects.

\section{Keywords}

Executive orders; immigration policy; judicial review; temporary restraining order. 


\section{SUMARIO}

I. ASPECTOS DE LA JUSTICIA CONSTITUCIONAL EN LOS ESTADOS UNIDOS: CONTROL DE CONSTITUCIONALIDAD Y PROTECCIÓN O AMPARO A LOS DERECHOS FUNDAMENTALES. II. LA ORDEN EJECUTIVA DEL PRESIDENTE DONALD J. TRUMP SOBRE MATERIA INMIGRATORIA Y SU IMPUGNACIÓN. III. LAS PRIMERAS ACCIONES CONTRA LA ORDEN EJECUTIVA ANTE DIVERSAS CORTES FEDERALES DE DISTRITO. IV. LA DEMANDA INTENTADA POR EL ESTADO DE WASHINGTON CONTRA LA ORDEN EJECUTIVA Y LA DECISIÓN CAUTELAR DE SUSPENSIÓN DE SUS EFECTOS A NIVEL NACIONAL POR LA CORTE FEDERAL DEL DISTRITO OESTE DEL ESTADO DE WASHINGTON DE 3 DE FEBRERO DE 2017: 1. La demanda del estado de Washington a la cual se sumó el estado de Minnesota. 2. La decisión sobre la medida cautelar de amparo y su fundamento legal. 3. La puntualización final de la sentencia, a manera de conclusión, sobre los poderes de los jueces federales en materia de control de constitucionalidad. 4. Los ataques del poder ejecutivo contra el juez de distrito, la independencia judicial y la apelación. V. LA CONFIRMACIÓN DE LA MEDIDA CAUTELAR DE SUSPENSIÓN DE EFECTOS DE LA ORDEN EJECUTIVA POR PARTE DE LA CORTE DE APELACIONES DEL NOVENO CIRCUITO POR SENTENCIA DE 9 DE FEBRERO DE 2017: 1. La reafirmación de su propia competencia por la Corte de Apelaciones. 2. La decisión sobre la legitimación activa de los estados para demandar en este caso. 3. Sobre el poder de las cortes federales para controlar la constitucionalidad de los actos ejecutivos. 4. Sobre la incompetencia de funcionarios federales subalternos para modificar la Orden Ejecutiva. 5. Sobre el ámbito de aplicación de la medida cautelar adoptada por el juez de distrito, con ámbito de nivel nacional. VI. APRECIACIÓN FINAL.

El viernes 27 de enero de 2017, el presidente de los Estados Unidos Donald J. Trump emitió una "Orden Ejecutiva para proteger la Nación de la entrada de terroristas extranjeros a los Estados Unidos» 82 Fed. Reg. $8977^{1}$. Se trató de un acto ejecutivo de carácter reglamentario dictado conforme a los

1 Véase en https://www.whitehouse.gov/the-press-office/2017/01/27/executive-orderprotecting-nation-foreign-terrorist-entry-united-states. 
poderes que la Constitución y las leyes le otorgan al jefe del Poder Ejecutivo, y entre ellas, la Immigration and Nationality Act (INA), 8 U.S.C. 1101 et seq., y la sección 301 del título 3 del United States Code.

Contra dicha Orden Ejecutiva se intentaron de inmediato diversas acciones judiciales buscando la protección de derechos fundamentales de las personas afectadas, mediante la declaración de su inconstitucionalidad, entre las cuales destacó la acción de invalidación por razones de constitucionalidad con petición de amparo constitucional (preliminary injunction) intentada por dos estados de la Unión norteamericana, los estados de Washington y Minnesota, con solicitud de suspensión parcial de los efectos de la misma (en relación con las secciones 3.c, 5.a, 5.b, 5.c y 5.e), ante el juez federal de distrito del Distrito Oeste del estado de Washington.

Con la acción se formuló adicionalmente una petición para la emisión de una medida de amparo cautelar, una temporary restraining order, la cual, en definitiva, fue acordada por el juez de distrito mediante decisión del 3 de febrero de 2017, que fue ratificada por la Corte de Apelaciones del Noveno Circuito con sede en San Francisco, de fecha 9 de febrero de 2017.

Nuestro propósito en este comentario es analizar las principales cuestiones jurídicas debatidas en el proceso hasta la ratificación en segunda instancia de la medida cautelar, y sus vicisitudes procesales, para lo cual nos referiremos antes a algunas líneas generales del control de constitucionalidad y de la protección judicial de los derechos fundamentales en los Estados Unidos.

\section{ASPECTOS DE LA JUSTICIA CONSTITUCIONAL EN LOS ESTADOS UNIDOS: CONTROL DE CONSTITUCIONALIDAD Y PROTECCIÓN O AMPARO A LOS DERECHOS FUNDAMENTALES}

En los Estados Unidos, como es sabido, el control de constitucionalidad de las leyes y demás actos estatales, como es el caso de las órdenes ejecutivas dictadas por el presidente, se ejerce por todos los tribunales mediante el denominado método difuso de control de constitucionalidad, que deriva del principio de la supremacía constitucional, y que tiene su fundamento en la "cláusula de supremacía» contenida en el art. VI, sección 2 de la Constitución. Dicho principio fue desarrollado a partir de 1803 en el conocido caso Marbury vs. Madison 3 US (1 Cranch) 137, (1803), en el cual el juez John Marshall consideró que si la Constitución es la ley suprema de un país y, como tal, prevalece sobre las otras leyes, ningún otro acto del Estado que sea contrario a la Constitución puede ser una ley efectiva y, al contrario, debe ser considerado como nulo. En sus propias palabras, si la Constitución es «la ley fundamental y suprema de una nación... un acto del legislador que repugne a 
la Constitución es nulo». Por tanto, la supremacía de la Constitución implica que los actos que colisionen con la misma son, en efecto, nulos, y como tales, así tienen que ser considerados por los tribunales, los cuales son, precisamente, los órganos estatales llamados a aplicar las leyes².

Por ello, en los Estados Unidos, todos los tribunales deben en consecuencia decidir los casos concretos que están considerando, como se sostuvo en el mismo caso Marbury vs. Madison 5 US (1 Cranch), 137 (1803), "conforme a la Constitución desaplicando la ley inconstitucional», siendo esta «la verdadera esencia del deber judicial». En consecuencia, en el método difuso de control de la constitucionalidad, este rol corresponde a todos los jueces y no solo a una Corte Suprema, y no debe ser solo visto como un poder atribuido a los tribunales, sino como un deber de los mismos para decidir conforme a las reglas constitucionales, desaplicando las leyes contrarias a sus normas ${ }^{3}$.

Dicho control judicial de constitucionalidad en ningún caso es un control abstracto, sino que solo puede realizarse en un proceso en curso ante un tribunal, lo que implica que el control de constitucionalidad es siempre de carácter incidental, en el sentido de que la cuestión de inconstitucionalidad de una ley u otro acto estatal y su inaplicabilidad, se plantea en un caso o proceso concreto (cases and controversies), cualquiera sea su naturaleza, en el cual la aplicación o no de una norma concreta es considerada por el juez como relevante para la decisión del caso.

En consecuencia, en el método difuso de control de constitucionalidad, el thema decidendum, es decir, el objeto principal del proceso y de la decisión judicial no es la consideración abstracta de la constitucionalidad o inconstitucionalidad de la ley o acto ejecutivo o su aplicabilidad o inaplicabilidad, sino, más bien, la decisión de un caso concreto, por ejemplo, en materia civil, penal, administrativa, mercantil, laboral, de protección de algún derecho constitucional, etc., en el cual la cuestión de constitucionalidad es un aspecto incidental en el proceso que solo debe ser considerada por el juez para resolver la aplicabilidad o no de una ley en la decisión del caso concreto, cuando surgen cuestiones relativas a su inconstitucionalidad.

2 Véase sobre el sistema norteamericano de justicia constitucional en el marco del derecho comparado Allan R. Brewer-Carías (1989), Judicial Review in Comparative Law, Cambridge: Cambridge University Press y (2014), Judicial Review. Comparative Constitucional Law Essays, Lectures and Courses (1985-2011), Caracas: Fundación de Derecho Público, Editorial Jurídica Venezolana.

3 En general sobre el método difuso de control de constitucionalidad véase Allan $\mathrm{R}$. Brewer-Carías (2010), «El método difuso de control de constitucionalidad de las leyes en el derecho venezolano», en Víctor Bazán (coord.), Derecho Procesal Constitucional Americano y Europeo, Buenos Aires: Edit. Abeledo-Perrot, tomo I, págs. 671-690. 
Por eso la decisión del juez en materia de constitucionalidad en el método difuso solo tiene efecto inter partes, pudiendo alcanzar efectos generales erga omnes cuando el asunto llega por ejemplo a la Corte Suprema, en virtud del principio del precedente (stare decisis).

Por otra parte, en el sistema judicial norteamericano, en cuanto a la protección efectiva de los derechos fundamentales, la misma se asegura mediante los remedios judiciales ordinarios del proceso o a través de remedios extraordinarios de equidad (como las injunctions), las cuales también se utilizan para la protección de cualquier tipo de derechos o intereses de las personas (civil rights injunctions). Estas injunction tienen su equivalente en los sistemas latinoamericanos, en las acciones o peticiones de amparo constitucional de los derechos fundamentales, en particular en los sistemas de amparo difuso que existen en la mayoría de los países de América Latina, donde todos los tribunales de primera instancia son competentes para conocer de las acciones de amparó ${ }^{4}$.

$\mathrm{Al}$ igual que en materia de amparo, las injunctions son también acciones que en principio son in personam, por lo cual el accionante debe ser precisamente la persona agraviada, que tiene un interés personal en el caso y su resultado 5 . Por ello, para intentar una injunction, el demandante debe evidenciar daños actuales, sustanciales y graves o una posibilidad cierta de tales daños; es decir, un demandante no tendrá derecho a una injunction cuando un dańo en su contra no se evidencie como resultante de la actividad que se denuncia o se procura evitar ${ }^{6}$.

Sin embargo, en materia de protección de derechos humanos, en los Estados Unidos, a algunos funcionarios públicos, y en particular a los Attorney

4 Véanse, sobre los sistemas de protección judicial de los derechos fundamentales en el derecho comparado, Allan R. Brewer-Carías (2008), Constitucional Protection Of Human Rights In Latin America. A Comparative Study of the Amparo Proceedings, New York: Cambridge University Press y (2016), El Proceso de Amparo en el Derecho Constitucional Comparado de América Latina, México: Colección Biblioteca Porrúa de Derecho Procesal Constitucional, Porrúa.

5 Véase Kevin Schroder et al. (2004), «Injunction», Corpus Juris Secundum, Thomson West, vol. 43A; M. Glenn Abernathy y Barbara A. Perry (1993), Civil Liberties Under the Constitution, University of South Carolina Press, pág. 4. Véase el caso Alabama Power Co. v. Alabama Elec. Co-op., Inc., 394 F.2d 672 (5 Cir. 1968), en John Bourdeau et al. (2004), "Injunctions», en Kevin Schroder, John Glenn y Maureen Placilla (eds.), Corpus Juris Secundum, vol. 43A, West, pág. 229.

6 Véase U.S. Boyle v. Landry, 401 U.S. 77, 91 S. Ct.758, 27 L. Ed. 2 d 696 (1971), en John Bourdeau et al. (2004), «Injunctions», en Kevin Schroder, John Glenn y Maureen Placilla (eds.), Corpus Juris Secundum, vol. 43A, Thomson West, pág. 66. 
General, se los ha considerado con suficiente legitimación activa para intentar injunctions ${ }^{7}$, lo cual se generalizó después de la Sentencia de la Suprema Corte en el caso Brown v. Board of Education of Topeka 347 U.S. 483 (1954); 349 U.S. 294 (1955), al declarar inconstitucional el sistema escolar dual («separados pero iguales»). Después de esta sentencia y mediante la Ley de Derechos Civiles de 1957, el Congreso comenzó a autorizar al procurador general para que interpusiera injunctions en protección de los derechos humanos, particularmente con el fin de implementar la Décimo Quinta Enmienda al referirse, por ejemplo, al derecho de votar sin discriminaciones ${ }^{8}$. La consecuencia de estas reformas ha sido que el procurador general, al representar a los Estados Unidos, ha dejado de participar en procesos de derechos civiles como amicus curie solamente, y ha jugado un papel prominente incoando injunctions en protección de derechos civiles", procurando la protección, por ejemplo, en materia de seguridad y salud públicas ${ }^{10}$.

El resultado final de la petición de injunction, luego de asegurarse el debido proceso y por tanto la participación en el juicio de los demandados,

7 El procurador general, por supuesto, ha tenido la legitimación requerida para la protección del interés general del Estado, por ejemplo, en el control del servicio de correos, como lo admitió la Corte Suprema en sentencia In Re Debs, 158 U.S. 565, 15 S.Ct. 900,39 L.Ed. 1092 (1895), siendo en tal caso la parte contra los miembros de un sindicato de trabajadores de ferrocarriles que amenazaban el funcionamiento de los trenes. Unos años antes, el Congreso, mediante la ley Sherman, contra los monopolios, atribuyó facultad al procurador general para activar procesos de injunctions a fin de impedir restricciones al comercio.

8 Véase lo señalado por Owen R. Fiss: «La iniciativa legislativa inmediatamente siguiente — la Ley de Derechos Civiles de 1960 - fue dispuesta en gran parte para perfeccionar las armas de injunctions del procurador general en favor del derecho al sufragio. En cada una de las siguientes leyes sobre derechos civiles — las de 1964 y 1968 - se repitió el mismo patrón: se autorizó al procurador general para incoar medidas de injunction a fin de exigir el cumplimiento de una amplia gama de derechos — servicios públicos (p. ej., restaurantes), instalaciones estatales (p. ej., parques), escuelas públicas, empleos y vivienda—». Véase Owen M. Fiss (1978), The Civil Rights Injunction, Bloomington-London: Indiana University Press, pág. 21.

9 Véase Owen M. Fiss y Doug Rendleman (1984), Injunctions, 2a . ed., Mineola, New York: University Casebook Series, The Foundation Press, pág. 35.

10 Por eso, por ejemplo, los procedimientos de injunctions en casos del ejercicio ilegal de la medicina y de otras profesiones conexas han sido interpuestas por el procurador general, una Comisión Estatal de Salud y un abogado del condado, v., por ejemplo, State ex rel. State Bd. Of Healing Arts v. Beyrle, 269 Kan. 616, 7 P3d 1194 (2000), Idem, págs. 276 ss. 
quienes tienen derecho a ser oídos ${ }^{11}$, es en todo caso una decisión judicial u orden dictada por el tribunal para la protección de los derechos amenazados o para la restitución del disfrute del derecho lesionado, la cual puede consistir, por ejemplo, en una decisión ordenando o previniendo una actuación o en una orden de hacer, no hacer o deshacer alguna acción ${ }^{12}$. Esto quiere decir que el mandamiento de amparo, como la injunction norteamericana ${ }^{13}$, es un decreto judicial de protección judicial de los derechos fundamentales.

En el juicio iniciado por los estados de Washington y Minnesota contra Donald J. Trump y los otros altos funcionarios del Poder Ejecutivo con motivo de la Orden Ejecutiva sobre política de inmigración de 7 de enero de 2017, comenzó mediante la interposición de una acción cuyo objeto fue la declaratoria de invalidación de dicha orden por los daños que causaba a dichos estados y a derechos de sus residentes, solicitando su declaratoria de invalidez por inconstitucional; acción que además se acompañó de una petición de protección de derechos constitucionales que se consideraron violados, mediante una preliminar injunction, que, como se dijo, es similar a una pretensión de amparo constitucional; a lo que se agregó una petición para que se dictase una medida cautelar, una temporary restraining order, para suspender los efectos de la decisión impugnada mientras dura el juicio, en sentido equivalente a las peticiones de amparo cautelar en algunos derechos latinoamericanos.

11 De manera similar, respecto de las injunctions definitivas, estas solo pueden declararse si se libra compulsa de la demanda y se ha hecho citación del accionado. Véanse, por ejemplo, los casos U.S. v. Crusco, 464 F.2d 1060, Cir. 1972, Murphy v. Washington American League Baseball Club, Inc., 324 F2d. 394, D.C. Cir. 1963, en John Bourdeau et al. (2004), «Injunctions», en Kevin Schroder, John Glenn y Maureen Placilla, Corpus Juris Secundum, vol. 43A, Thomson West, pág. 339.

12 En la injunction de los Estados Unidos, la orden puede ser ejecutiva o preventiva de virtualmente cualquier tipo de acción (Dawkins v. Walker, 794 So. 2d 333, Ala. 2001; Levin v. Barish, 505 Pa. 514, 481 A.2d 1183, 1984) o puede ordenar a alguien que deshaga un ilícito o un daño (State Game and Fish Com’n v. Sledge, 344 Ark. 505, 42 S.W.3d 427, 2001). Es una orden judicial demandando a una persona a hacer o abstenerse de hacer determinados actos (Skolnick v. Altheimer \& Gray, 191 Ill 2d 214, 246 Ill. Dec. 324, 730 N.E.2d 4, 2000), por cualquier periodo de tiempo independientemente de su propósito (Sheridan County Elec. Co-op v. Ferguson, 124 Mont. 543, 227 P.2d 597, 1951). Ibid., pág. 19.

13 Véase el caso Nussbaum v. Hetzer, 1, N.J. 171, 62 A. 2 d 399 (1948). Ibid., pág. 19. 


\section{LA ORDEN EJECUTIVA DEL PRESIDENTE DONALD J. TRUMP SOBRE MATERIA INMIGRATORIA Y SU IMPUGNACIÓN}

La Orden Ejecutiva impugnada relativa a temas inmigratorios adoptada por el presidente Donald J. Trump el 27 de enero de $2017^{14}$, a los pocos días de la toma de posesión del presidente, en cumplimiento de una de las promesas electorales formuladas durante la campaña presidencial de 2016, que en su momento no habían dejado de no originar polémicas, y que fue, sin embargo, emitida en una forma relativamente inconsulta con los departamentos con responsabilidad en la materia en el Gobierno Federal ${ }^{15}$, tuvo como propósito corregir las fallas existentes en el sistema de control de otorgamiento de visas de entrada de extranjeros, que no habría funcionado completamente incluso después de las reformas introducidas luego del ataque terrorista ocurrido en Nueva York el 11 de septiembre de 2001. En la misma se planteó que los Estados Unidos no debía admitir a quienes no apoyasen la Constitución o que pudieran pretender colocar ideologías violentas sobre la ley americana; ni a quienes realizasen acciones de odio (como los asesinatos de «honor»y otras formas de violencia contra la mujer, o persecuciones religiosas), ni a quienes pudieran oprimir a los americanos de cualquier raza, género u orientación sexual.

Con base en lo anterior, el presidente definió como política en la Orden Ejecutiva, la de "proteger a sus ciudadanos de los extranjeros que intenten cometer ataques terroristas en los Estados Unidos, y prevenir la admisión de extranjeros que intenten utilizar las leyes de inmigración americanas con propósitos malévolos» (sección 2), estableciendo para ello una serie de medidas, entre ellas «la suspensión del otorgamiento de visas y otros beneficios de inmigración a nacionales de determinados países de particular preocupación» (sección 3), ordenando a los órganos ejecutivos competentes la realización de

14 Véase el texto en https:/www.whitehouse.gov/the-press-office/2017/01/27/executive-order-protecting-nation-foreign-terrorist-entry-united-states.

15 La Orden fue emitida, según reportó la prensa, sin la opinión legal del Departamento de Homeland Security. Véase lo expresado por John F. Kelly, secretario de Homeland Security, en Michael D. Shear y Ron Nixon, «How a Rushed Order Ignited Global Confusion», The New York Times, New York, 30 de enero de 2017, pág. A1. Véase igualmente, en Damian Paletta y Aruna Viswanatha, «Homeland Chief and Withe House Clash", The Wall Street Journal, New York, 31 de enero de 2017, pág. A5. El secretario Kelly igualmente ratificó ante el Congreso que la decisión había sido adoptada con extrema rapidez, y que debió haberse discutido con el Congreso. Véase Laura Meckler y Aruna Viswanatha, «Kelly Says Ban Was Rushed», The Wall Street Journal, New York, 8 de febrero de 2017, pág. A4. 
las actividades administrativas y presentación de informes necesarios para ello, y proclamando, entre otras medidas, como la más destacada, en la sección 3.c:

Que la entrada de extranjeros inmigrantes o no inmigrantes de los países indicados en la sección 217(a)(12) del INA, 8 U.S.C. 1187(a)(12), es perjudicial para los intereses de los Estados Unidos, y en consecuencia suspende la entrada en los Estados Unidos, como inmigrantes o no inmigrantes, a dichas personas por 90 días desde la fecha de esta Orden (excluyendo los extranjeros viajando con visas diplomáticas, visas de la Organización del Atlántico Norte, visas C-2, visas para viajes a las Naciones Unidas, y visas G-1, G-2, G-3, y G-4).

Esos países enumerados en dichos estatutos son: Irán, Iraq, Libia, Somalia, Sudán, Siria y Yemen.

La misma Orden Ejecutiva también dispuso una «Reordenación del Programa de Admisión de Refugiados en los Estados Unidos para el año fiscal 2017» (sección 5), ordenando la suspensión de dicho programa por 120 días (sección 5.a), estableciendo de antemano que cuando se reasuma, deberá darse prioridad a personas perseguidas por motivos religiosos, cuando dicha religión sea minoritaria en el país de la nacionalidad (sección 5.b). Además, en la misma Orden Ejecutiva, el presidente proclamó conforme a la sección 212(f) de la INA, 8 U.S.C. 1182(f), que:

[...] la entrada de nacionales de Siria como refugiados es prejudicial a los intereses de los Estados Unidos y en consecuencia suspende cualquier entrada de los mismos hasta que yo determine que suficientes cambios se han efectuado a la USRAP para asegurar que la admisión de refugiados de Siria es consistente con el interés nacional (sección 5.c).

\section{LAS PRIMERAS ACCIONES CONTRA LA ORDEN EJECUTIVA ANTE DIVERSAS CORTES FEDERALES DE DISTRITO}

Dada la instrucción de implementación inmediata que contuvo la Orden Ejecutiva, al comenzar a aplicarse lo que produjo fue confusión y caos precisamente durante todo el fin de semana del 28 y 29 de enero que siguió a su adopción, particularmente en los principales aeropuertos de los Estados Unidos, donde fueron detenidos e incluso deportados muchos nacionales de los países vetados, incluso aun siendo residentes legales en el país o teniendo visa de entrada legalmente expedida. Como lo resumió la Corte de Apelaciones del Noveno Distrito con sede en San Francisco en su Sentencia de 9 de febrero de 2017 (State of Washington et al. v. Donald Trump et al.), que se comenta más adelante: 
El impacto de la Orden Ejecutiva fue inmediato y extendido. Fue reportado que miles de visas fueron canceladas inmediatamente, cientos de viajeros con visas fueron impedidos de abordar aviones hacia los Estados Unidos, o les fue negada la entrada a su llegada, y algunos viajeros fueron detenidos ${ }^{16}$.

Ello provocó que diversas personas intentaran acciones judiciales de amparo ante los jueces locales buscando protección de los derechos de varios de los extranjeros detenidos y amenazados de deportación, asistidos por asociaciones y organizaciones no gubernamentales de derechos humanos, y entre ellas, por la American Civil Liberties Union ${ }^{17}$.

Esta actividad judicial originó que al día siguiente de dictada la Orden Ejecutiva, el sábado 28 de enero de 2017 en la noche, la juez Ann Donnelly, de la Corte Federal del Distrito Este de Nueva York, en Brooklyn, dictara una temporary injunction (amparo cautelar) en protección de los derechos al debido proceso e igualdad de unos nacionales iraquíes (caso Hameed Khalid Darwesh et al. vs. Donald Trump et al.) detenidos en el aeropuerto J. F. Kennedy en Nueva York, prohibiendo que fueran deportadas aquellas personas con solicitudes de refugiado aprobadas, o titulares de visas válidas y otros individuos de Iraq, Siria, Irán, Sudán, Libia, Somalia y Yemen con autorización legal de entrada a los Estados Unidos ${ }^{18}$.

En sentido similar decidieron otras tres Cortes Federales de Distrito en otras partes de los Estados Unidos ${ }^{19}$, en las ciudades de Boston (juez Allison D. Burroughs), Alexandria (juez Leonie M. Berinkema) y Seattle (juez Yhomas S. Zilly), no solo prohibiendo la deportación sino la detención de los extranjeros con autorización de entrada en los Estados Unidos ${ }^{20}$.

La consecuencia inmediata de esta actividad judicial fue la enmienda realizada por el consultor jurídico de la Casa Blanca, que se reflejó en la precisión que hizo el Department of Homeland Security excluyendo de la aplicación de la Orden Ejecutiva a los tenedores de residencia permanente (green card) que

16 Véase el texto en https://cdn.ca9.uscourts.gov/datastore/opinions/2017/02/09/17-35105. pdf.

17 Véase la información en The New York Times, New York, 28 de enero de 2017, en https://www.nytimes.com/2017/01/28/us/refugees-detained-at-us-airports-prompting-legal-challenges-to-trumps-immigration-order.html?_r=0; y en The Wall Street Journal, New York, 30 de enero de 2017, pág. 5.

18 Véase en https://assets.documentcloud.org/documents/3437026/Darweesh-v-TrumpOrder-on-Emergency-Motion-For.pdf.

19 Véase la información en The Wall Steet Journal, New York, 30 de enero de 2017, pág. 4.

20 Véase en Adam Liptak, «Rulings Blocking Parts of Trump's Order Are the First Step on a Long Legal path», The New York Times, New York, 30 de enero de 2017, pág. A10. 
estuviesen regresando al país ${ }^{21}$. Luego fue anunciada una segunda enmienda en el sentido de que la Orden no se aplicaría a los iraquíes que habían trabajado como intérpretes para los Estados Unidos ${ }^{22}$.

En todos los casos judiciales, las acciones intentadas plantearon la inconstitucionalidad de la Orden Ejecutiva, y si bien en los mismos se acordaron amparos cautelares, de orden temporal, ello fue mientras se desarrollaban los juicios en los cuales el Gobierno Federal debía intervenir como demandante.

El lunes 30 de enero de 2017, la abogado Sally Yates, encargada de la Oficina del attorney general de los Estados Unidos, ya que su titular había renunciado por el cambio de gobierno y no había aprobado al sucesor en el Senado, consciente de la inconstitucionalidad que afectaba la Orden Ejecuti$\mathrm{va}^{23}$, instruyó a los servicios del Departamento de Justicia que no defendieran en las Cortes la Orden Ejecutiva, lo que fue considerado por la Casa Blanca como una "traición al Departamento de Justicia» habiendo sido despedida por ello de su cargo el mismo día 30 de enero ${ }^{24}$.

Ese mismo día, el gobernador del Estado de Washington y el attorney general del mismo, Bob Ferguson, anunciaron que intentarían una demanda judicial contra la Orden Ejecutiva con mayor amplitud que las que se habían intentado hasta el momento, buscando invalidarla a nivel nacional, por inconstitucional y violatoria de la ley federal, considerando que se trataba de un ataque frontal contra la fe musulmana que podía dañar los negocios y las personas en el Estado, anunciando que la demanda estaría acompañada de testimonios de grandes empresas como Amazon y Expedia, sobre el carácter dañoso de la orden del presidente Trump ${ }^{25}$.

21 Véase Peter Baker, «Trump Modifies Ban On Migrants as Outcry Grows», The New York Times, New York, 30 de enero de 2017, págs. A1 y A11.

22 Véase David Zucchino, "Visa Ban Is Amended to Allow Iraqi Interpreters Into US», The New York Times, New York, 3 de febrero de 2017, pág. A19.

23 La abogado Yates expresó que: «Actualmente, no estoy convencida que la defensa de la Orden Ejecutiva sea consistente con mis responsabilidades, ni estoy convencida de que la Orden Ejecutiva sea legal». Véase en Michael D. Shear, Mark Landler, Matt Apuzzo y Eric Lichtblau, "Trump Fires Justice Chief who Defied Him», The New York Times, New York, 31 de enero de 2017, págs. A1, A12.

24 Véase Damian Paletta y Aruna Viswanatha, "President Outs Acting Justice Chief», The Wall Street Journal, New York, 31 de enero de 2017, pág. A1.

25 Véase Alexander Burns, «Legal Challenges Mount Against Travel Ban Ordered by Trump», The New York Times, 31 de enero de 2017, págs. A8, y "How Washington State Banded Together to halt Trump's Travel Decree», The New York Times, New York, 5 de febrero de 2017, pág. 13. 
Adicionalmente, el attorney general del Estado de Massachusetts anunció que se haría parte en el proceso que se había iniciado en Boston por la American Civil Liberties Union, alegando contra la Orden Ejecutiva daños contra las instituciones del Estado, incluyendo la Universidad de Massachusetts, donde estudiantes y profesores serían directamente afectados por esta, forzando a dichas instituciones a discriminar ilegalmente a las persona por su religión o por su país de origen ${ }^{26}$.

Adicionalmente, el Consejo de las Relaciones Americanas-Islámicas intentó otra demanda en Virginia representando a 27 musulmanes residentes en los Estados Unidos que se consideraba serían afectados por la Orden Ejecutiva, calificándola como una «Orden de Exclusión de Musulmanes» citando lo que el presidente Trump había definido como política durante su campaña para las primarias en su nominación como candidato presidencial, de que cerraría la inmigración musulmana en los Estados Unidos ${ }^{27}$.

\section{LA DEMANDA INTENTADA POR EL ESTADO DE WASHINGTON CONTRA LA ORDEN EJECUTIVA Y LA DECISIÓN CAUTELAR DE SUSPENSIÓN DE SUS EFECTOS A NIVEL NACIONAL POR LA CORTE FEDERAL DEL DISTRITO OESTE DEL ESTADO DE WASHINGTON DE 3 DE FEBRERO DE 2017}

\section{LA DEMANDA DEL ESTADO DE WASHINGTON A LA CUAL SE SUMÓ EL ESTADO DE MINNESOTA}

Tal como se había anunciado, el mismo día 30 de enero de 2017, el Estado de Washington efectivamente intentó ante la Corte Federal del Distrito Oeste de Washington en Seattle, a cargo del juez James Robart, una demanda contra «Donald J. Trump, en su carácter oficial de Presidente de los Estados Unidos, el Departamento de Homeland Security de los Estados Unidos, John F. Kelly, en su carácter oficial de Secretario del Departamento de Homeland Security, Tom Shannon, en su carácter oficial de Secretario de Estado encargado, y los Estados Unidos de América» como demandados, solicitando la invalidación de la antes identificada Orden Ejecutiva dictada por el presidente Trump el 29 de enero de 2017, junto con una petición de amparo (injunctive relief) buscando la suspensión de los efectos de dicha

\footnotetext{
26 Véase Alexander Burns, «Legal Challenges Mount Against Travel Ban Ordered by Trump», The New York Times, 31 de enero de 2017, pág. A8.

27 Idem.
} 
orden. Con fecha 1 de febrero de 2017, el Estado de Washington modificó la demanda ańadiendo a la misma como demandante al Estado de Minnesota.

Los argumentos formulados por la solicitor general del Estado de Washington, Noah G. Putcell, para solicitar la protección de la Corte respecto de las personas que viven en el Estado y cuyas vidas estimó que cambió de repente con la Orden Ejecutiva, estuvieron enfocados en relación con:

[...] las personas que han estado aquí y de la noche a la mañana han perdido su derecho a viajar, su derecho a visitar sus familias, su derecho a investigar, su derecho de hablar y dar conferencias alrededor del mundo. Y también personas que han vivido aquí por mucho tiempo y que por casualidad estaban en el exterior al momento de la emisión de la Orden, que se adoptó sin aviso de ninguna clase, perdieron de repente su derecho a regresar a los Estados Unidos ${ }^{28}$.

Como lo resumió la Corte de Apelaciones del Noveno Circuito en su decisión del 9 de febrero de 2017, que se comenta más adelante, para la solicitud de declaratoria parcial de inconstitucionalidad e legalidad de la Orden Ejecutiva:

Washington alegó que la Orden Ejecutiva dejó varadas inconstitucional e ilegalmente en el exterior a residentes, separó sus familias, restringió sus viajes, y dañó a la economía del Estado y a las universidades públicas en violación de la Primera y Quinta Enmienda, la Ley de Inmigración Nacional, la Ley de reforma y reestructuración de Asuntos Exteriores, la Ley de Restauración de la Libertad Religiosa y la Ley de Procedimiento Administrativo. Washington también alegó que la Orden Ejecutiva no estaba en verdad destinada a proteger contra ataques terroristas por nacionales extranjeros, sino más bien estuvo destinada a establecer una «Prohibición Musulmana» como el Presidente afirmó que lo haría durante su campaña presidencial.

El mismo día de presentada la demanda, el estado de Washington formuló una petición de emergencia para la emisión de una medida cautelar (temporary restraining order) de suspensión de la aplicación de las secciones 3(c), 5(a)-(c), and 5(e) de la Orden Ejecutiva, con el objeto de preservar el statu quo hasta que la Corte realizara la Audiencia para decidir sobre la moción de amparo (preliminary injunction) que se formuló con la demanda. Posteriormente, el juez Robart procedió a efectuar la audiencia respectiva, luego de la oposición del Gobierno Federal respecto de dicha medida, como consecuencia de lo cual pasó a dictar sentencia el 3 de febrero de 2917 (caso Washing-

28 Véase Adam Liptak, "The President has Much Power Over Immigration, but How Much?», The New York Times, New York, 6 de febrero de 2017, pág. A11. 
ton v. Trump, No. C17-0141-JLR, 2017 WL 462040 -W.D. Wash. Feb. 3, 2017— ${ }^{29}$, solo sobre la referida petición de la medida cautelar que intentaron los demandantes ${ }^{30}$.

\section{LA DECISIÓN SOBRE LA MEDIDA CAUTELAR DE AMPARO Y SU FUNDAMENTO LEGAL}

Para decidir la petición de medida cautelar (temporary restraining order) formulada, el juez comenzó por declarar su jurisdicción para conocer de la demanda contra los demandados federales, constatando que los estados habían realizado los esfuerzos necesarios para contactarlos, habiendo cumplido razonable y sustancialmente con el requerimiento establecido en la Federal Rule of Civil Procedure 65(b); habiendo dichos demandados comparecido y defendido su posición ante la Corte.

En cuanto a la medida cautelar solicitada, el juez constató que los requisitos para dictarla son los mismos que los exigidos para dictar una preliminary injunction $^{31}$, considerando que la temporary restraining order, como cualquier medida cautelar en los derechos latinoamericanos, es un «remedio extraordinario que solo puede acordarse cuando hay una clara evidencia de que el demandante es acreedor de tal medida $»^{32}$, considerando además que los requisitos para acordar un preliminary injunctive relief son que la parte demandante haya demostrado:

(1) que es muy probable que triunfe en cuanto al mérito; (2) que es muy probable que sufra un daño irreparable en ausencia de remedio preliminar (3) que el balance de equidad se inclina a su favor; y 4) que la injunction es en interés público ${ }^{33}$.

29 Véase en https://assets.documentcloud.org/documents/3446145/WA-Order.pdf.

30 La Corte citó en apoyo sobre la naturaleza de la orden restrictiva temporal la Sentencia Granny Goose Foods, Inc. v. Bhd. Of Teamsters \&Auto Truck Drivers Local No. 70 of Alameda City, 415 U.S. 423, 439 (1974); Am. Honda Fin. Corp. v. Gilbert Imports, LLC, No. CV-13-5015-EFS, 2013 WL 12120097, at*3 (E.D. Wash. Feb. 22, 2013), en la cual se estableció que: «El propósito de la Temporary Restraining Order es preservar el status quo hasta que haya una oportunidad to realizar una audiencia en relación con la aplicación de la preliminary injunction....».

31 Cita de la Corte: New Motor Vehicle Bd. of Cal v. Orrin W. Fox Co., 434 U.S. 1345, 1347 n. 2 (1977).

32 Cita de la Corte: Winter v. Nat. Res. Def. Council, Inc., 555 U.S. 7, 24 (2008).

33 Cita de la Corte: Stormans, Inc. v. Selecky, 586 F.3d 1109, 1127 (9th Cir. 2009) (citing Winter, 555 U.S. at 20). 
Es decir, en otros términos, los mismos requisitos exigidos para dictar una medida cautelar en los derechos latinoamericanos, para lo cual el juez debe analizar, en primer término, el fumus boni iuris, con el objeto de concretar la presunción grave de violación o amenaza de violación del derecho constitucional alegado por la parte quejosa y que lo vincula al caso concreto; y en segundo lugar, el periculum in mora, es decir, la convicción de que el derecho debe ser preservado o restituido de forma inmediata, ante el riesgo inminente de causar un perjuicio irreparable a la parte que alega la violación.

Por ello, el juez precisó como test alternativo que una preliminary injunction es apropiada si "hay cuestiones serias envueltas en el mérito que se hayan planteado y que el balance de la privación se incline a favor del demandante», permitiendo por tanto la preservación del statu quo cuando cuestiones complejas requieran ulterior inspección y deliberación ${ }^{34}$. Sin embargo, admitió la Corte que la aproximación sobre las «cuestiones serias» envueltas en la petición apoyan la decisión de la Corte para otorgar una medida cautelar (temporary restraining order) «solo si el demandante también evidencia que existe una buena posibilidad de que se produzca un daño irreparable y de que la injunction es en interés público» ${ }^{35}$. La parte requirente tiene la carga de la persuasión y debe mostrar claramente que tiene derecho a la protección ${ }^{36}$.

Partiendo de estos principios, la Corte consideró que los estados demandantes habían satisfecho los estándares para otorgar la medida cautelar (temporary restraining order), y que debía entonces otorgarla. En particular consideró que los Estados había satisfecho los requisitos establecidos en el caso Winter, ya que habían demostrado que tenía buena probabilidad de triunfar en el mérito de la demanda que les da derecho a protección, que los Estados muy probablemente, en ausencia de la medida cautelar, sufrirían daños irreparables, que el balance de lo discutido favorecía a los Estados y que la medida cautelar era en interés público.

La Corte también encontró que los Estados habían satisfecho el test «alternativo» establecido en el caso Cottrell, porque habían establecido al menos cuestiones serias en relación con el mérito de su demanda y que el balance de los asuntos precisamente estaba a su favor. La Corte también consideró que, como en el test del caso Winter, los Estados establecieron una buena probabilidad de que se ocasionaría un daño irreparable, y que la medida cautelar (temporary restraining order) era en interés público.

34 Cita de la Corte: All. for the Wild Rockies v. Cottrell, 632 F.3d 1127,1134-35 (9th Cir. 2011).

35 Cita de la Corte: $I d$. at 1135.

36 Cita de la Corte: Winter, 555 U.S. at 22. 
Específicamente, a los efectos de otorgar la medida cautelar:

[...] la Corte encontró que los Estados han satisfecho la carga de demostrar que los mismos enfrentan un daño inmediato e irreparable como resultado de la firma e implementación de la Orden Ejecutiva. La Orden Ejecutiva afecta adversamente a los residentes de los Estados en áreas de empleo, educación, negocios, relaciones familiares y libertad de viajar. Estos dańos se extienden a los Estados en virtud de sus roles como parens patriae ${ }^{37}$ de los residentes que viven dentro de sus fronteras. Adicionalmente los Estados mismos están lesionados en virtud del daño que ha provocado la implementación de la Orden Ejecutiva en relación con las operaciones y misiones de sus universidades públicas y otras instituciones de alta educación, al igual que las lesiones a las operaciones, base impositiva y fondos públicos de los Estados. Estos daños son significantes y están en curso. En consecuencia, la Corte concluye que una Temporary Restraining Order contra los demandados federales es necesaria hasta que la Corte oiga y decida la demanda de los Estados sobre la preliminary injunction demandada.

En consecuencia con esta decisión, la Corte ordenó a los demandados: «Donald J. Trump, en su carácter oficial de Presidente de los Estados Unidos, el Departamento de Homeland Security de los Estados Unidos, John F. Kelly, en su carácter oficial de Secretario del Departamento de Homeland Security, Tom Shannon, en su carácter oficial de Secretario de Estado encargado, y los Estados Unidos de América», que ellos mismos y sus respectivos "oficiales, agentes, sirvientes, empleados, abogados y personas actuando en concierto o participando con ellos» están obligados a no cumplir con las secciones siguientes de la Orden Ejecutiva: sección 3.c; sección 5.a; sección $5 . \mathrm{b}$ o que procedan con cualquier acción que priorice reclamos de refugiados basados en ciertas minorías religiosas; sección 5.c; sección 5 .e en cuanto a que persigue priorizar reclamos de refugiados basados en ciertas minorías religiosas.

El juez aclaró en su decisión que, en todo caso, la medida cautelar otorgada era de ámbito nacional, prohibiendo la aplicación de las secciones mencionadas de la Orden Ejecutiva en todas las fronteras de los Estados Unidos y puertos de entrada hasta que se produzcan nuevas decisiones de la Corte. La Corte argumentó que aun cuando los demandados arguyeron que la medida cautelar debía limitarse a los estados demandantes, una implementación parcial de la Orden Ejecutiva «afectaría el principio constitucional de la Regla uniforme de Naturalización» y la instrucción del Congreso

37 Del latín "padre de la nación», en el sentido del poder inherente que tiene la autoridad en un Estado de proteger a las personas que no pueden legalmente actuar en su propio interés. 
de que las leyes de inmigración de los Estados Unidos deben ser aplicadas uniformemente ${ }^{38}$.

\section{LA PUNTUALIZACIÓN FINAL DE LA SENTENCIA, A MANERA DE CONCLUSIÓN, SOBRE LOS PODERES DE LOS JUECES FEDERALES EN MATERIA DE CONTROL DE CONSTITUCIONALIDAD}

La sentencia del juez de Distrito Robart concluyó con una serie de reflexiones sobre el tema de la importancia de la independencia judicial. El juez dijo:

Es fundamental para el trabajo de esta Corte, el reconocimiento vigilante de que es solo una de las tres ramas iguales de nuestro gobierno federal. El trabajo de la Corte no es crear una política o juzgar la sabiduría de cualquier política particular promovida por las otras dos ramas.

Ese es el trabajo de las ramas legislativa y ejecutiva y de los ciudadanos de este país quienes ultimadamente ejercen el control democrático sobre esas ramas. El trabajo de la Judicatura, y de esta Corte, está limitado a asegurar que las acciones adoptadas por las otras dos ramas se ajustan a las leyes de nuestro país, y aún más importante, a nuestra Constitución. La estrecha cuestión que esta Corte es llamada a considerar hoy es si es apropiado emitir una medida cautelar contra ciertas acciones adoptadas por el Ejecutivo en el contexto de esta específica demanda. Aun cuando la cuestión es estrecha, la Corte es consciente del considerable impacto que su orden puede tener en relación con las partes ante ella, la rama ejecutiva de nuestro gobierno y los ciudadanos y residentes del país. La Corte concluye que las circunstancias que se han traído hoy son tales que debe intervenir para llenar su rol constitucional en nuestro gobierno tripartido. En consecuencia, la Corte concluye que el otorgamiento de la antes descrita medida cautelar es necesaria y por tanto se declara con lugar la petición de los Estados.

Debe mencionarse que, en contraste con la decisión del juez Robart, en otra demanda ante la Corte de Distrito de Boston, el juez Nathaniel M. Gorton negó una petición similar de suspender la aplicación de la Orden Ejecutiva $^{39}$.

38 Cita de la Corte: Texas v. United States, 809 F.3d 134, 155 (5th Cir. 2015) (footnotes omitted) (quoting U.S. CONST, art. I, $\$ 8$, cl. 4 (emphasis added) and Immigration and Reform Control Act of 1986, Pub. L. No. 99-603, $\$ 115(1), 100$ Stat 3359, 3384 (emphasis added). An equally divided Supreme Court affirmed Texas v. United States, 809 F.3d 134, in United States v. Texas, — U.S._-136 S. Ct. 2271 (2016) (per curiam).

39 Véase la información en Adam Liptak, «The President Has Much Power Over Immigration, but How Much?», The New York Times, New York, 6 de febrero de 2017, pág. A11. 


\section{LOS ATAQUES DEL PODER EJECUTIVO CONTRA EL JUEZ DE DISTRITO, LA INDEPENDENCIA JUDICIAL Y LA APELACIÓN}

En todo caso, razón tenía el juez Robart de formular las conclusiones antes destacadas, pues no pasaron horas antes de que en el comunicado de la Casa Blanca se calificara la sentencia como «indignante» ${ }^{40}$, y de que el presidente Trump argumentara que la sentencia "ponía en peligro la seguridad de la nación», de manera que «si sucede algo en el país, cúlpenlo a él y al sistema judicial $»^{41}$. El presidente llegó a afirmar que:

La opinión de este llamado juez, que esencialmente elimina la aplicación de la ley de nuestro país, es ridícula y será revocada ${ }^{42}$.

Unos días después, el presidente comentó: «Si los Estados Unidos no ganan este caso como tan obviamente debe ganar, nunca podremos tener la seguridad a la cual tenemos derecho" ${ }^{43}$. Y agregó: «Pero parece que las Cortes son tan políticas, y sería muy grande para nuestro sistema judicial si las mismas fueran capaces de leer los argumentos y hacer lo que es correcto» ${ }^{44}$.

Los ataques del presidente Trump al juez Robart fueron altamente criticados, y sobre ellos, por ejemplo, el gobernador del Estado de Washington, demandante en el caso, los calificó como rayando «debajo de la dignidad» de la Presidencia, lo que podría «llevar a América a una calamidad» ${ }^{45}$. Incluso el

40 Véase Nicholas Kulish, Caitlin Dockerson y Charlie Savage, «Judge Issues Interim halt to Travel Ban», The New York Times, New York, 4 de febrero de 2017, pág. 1A.

41 Véase Peter Baker, «Legal Showdown over Immigrants Test Presidency», The New York Times, New York 6 de febrero de 2017, págs. A1, A10.

42 Véanse Mark Landeler, "Administration files an appeal of Travel Ruling», The New York Times, New York, 5 de febrero de 2017, págs. 1 y 12A, y Peter Baker, «Legal Showdown over Immigrants Test Presidency», The New York Times, New York, 6 de febrero de 2017, págs. A1, A10. Véase, sobre el ataque a los jueces por el presidente, el comentario del editorial «Mr. Trump Real Fear: The Courts», en The New York Times, New York, 7 de febrero de 2017, pág. A20.

43 Véase Beth Reinhard y Rebecca Balhaus, «Court Nominee Criticizes Trump's Attachs», The Wall Street Journal, 9 de febrero de 2017, pág. A14. Véanse los comentarios sobre las críticas del presidente Trump a los jueces en el editorial «The Quiet Grandeur of the Courts», The Wall Steet Journal, New York, 9 de febrero de 2017, pág. A26.

44 Véase Julie Hirschfeld Davis, «In Private, Supreme Court Choice Calls Trump's attack on Judiciary "Demoralizing"”, The New York Times, New York, 9 de febrero de 2017, pág. A16.

45 Véase Mark Lander, «Administration files an appeal of Travel Ruling», The New York Times, New York, 5 de febrero de 2017, pág. 12. 
juez Neil Gorsuch, nominado por el propio presidente Trump para juez de la Corte Suprema, expresó que los ataques de Trump al juez Robart eran «desmoralizadores y desalentadores» ${ }^{46}$. El vicepresidente de los Estados Unidos, Mike Pence, sin embargo, defendió al presidente argumentando que «tenía todo el derecho de criticar las otras dos ramas del gobierno. Y nosotros tenemos una larga tradición sobre ello en este país» ${ }^{47}$.

La sentencia del juez de distrito de Washington, cuyo cumplimento fue inmediato por parte de los departamentos del gobierno, fue apelada por el Gobierno Federal el sábado 4 de febrero de 2017, y el caso pasó a conocimiento de la Corte de Apelaciones del Noveno Circuito en San Francisco, la cual negó el domingo 5 de febrero de 2017 una solicitud urgente presentada por el Departamento de Justicia para que se restablecieran de forma inmediata los efectos de la Orden Ejecutiva ${ }^{48}$.

El argumento del Gobierno Federal fue que el juez Robart, en definitiva, cuestionaba el poder del presidente en materia de seguridad nacional y, en particular, en materia de inmigración, que conforme a la Constitución y a la ley federal es muy amplio ${ }^{49}$, no teniendo los jueces en la materia las herramientas necesarias para decidir, ya que «las Cortes no tienen acceso a información clasificada acerca de las amenazas de organizaciones terroristas operando en determinadas naciones, sus esfuerzos por infiltrar los Estados Unidos, o las fallas del proceso de veto [al ingreso de extranjeros]» $\aleph^{50}$. El Departamento de Justicia basó su argumentó en la extensión del poder del presidente en esta materia, cuando actúa, como en este caso, con autorización del Congreso, lo que lo coloca, citando el caso Youngstown Sheet \& Tube Co v. Sawyer, 1952, en el «ápex de su poder».

46 Véanse Beth Reinhard y Rebecca Balhaus, «Court Nominee Criticizes Trump's Attacks», The Wall Street Journal, New York, 9 de febrero de 2017, pág. A1; Julie Hirschfeld Davis, "Court Pick Says Trump's Censure is "Demoralizing”", The New York Times, New York, 5 de febrero de 2017, pág. A1.

47 Véase Peter Baker, «Legal Showdown over Immigrants Test Presidency», The New York Times, New York, 6 de febrero de 2017, pág. A10.

48 Véanse Devlin Barrett y Brent Kendall, "Appellate Standoff Looms Over Ban", The Wall Street Journal, 6 de febrero de 2017, pág. A1, y Peter Baker, «Legal Showdown over Immigrants Test Presidency», The New York Times, New York, 6 de febrero de 2017, pág. A1.

49 Véase Adam Liptak, "A look at the Case Stands», The New York Times, New York, 6 de febrero de 2017, pág. A10.

50 Véase la información en Adam Liptak, "The President has Much Power Over Immigration, but How Much?», The New York Times, New York, 6 de febrero de 2017, pág. A11. 
Los abogados del Estado de Washington, si bien aceptaron la extensión del poder presidencial para negarle la entrada a extranjeros al territorio americano cuando ello sea perjudicial a los intereses de los Estados Unidos, argumentaron, sin embargo, que dicho poder, por amplio que fuera, no podía ejercerse discriminando por raza, sexo, nacionalidad, lugar de nacimiento o lugar de residencia, que son las limitaciones establecidas en la ley en materia de otorgamiento de visas; y que la Orden violaba la Primera Enmienda en materia de libertad religiosa al establecer previsiones para refugiados favoreciendo religiones minoritarias; en definitiva, «inclinando la escala en favor de refugiados cristianos a costa de musulmanes», lo cual fue rechazado por la Administración Federal en sus argumentos ${ }^{51}$.

Ante la Corte de Apelaciones también se hicieron parte más de cien empresas tecnológicas oponiéndose a la Orden Ejecutiva por considerar que violaba la Constitución y que afectaba sus actividades ${ }^{52}$, e igualmente formularon alegatos sobre la inconstitucionalidad de la Orden Ejecutiva los attorney general de quince estados, entre ellos de Hawai, Distrito de Columbia, Nueva York, California, Massachusetts y Virginia, alegando que la misma «causaba dańos a los Estados, incluyendo sus instituciones como las universidades públicas, las empresas que sostienen nuestras economías y a nuestros residentes» ${ }^{53}$.

El procedimiento rápido y urgente se desarrolló ante la Corte de Apelaciones del Noveno Circuito, integrada por los jueces de circuito William C. Canby, Richard R. Clifton y Michelle T. Friedland, ante los cuales el 7 de febrero de 2017 las partes presentaron sus argumentos en audiencia pública ${ }^{54}$.

El presidente Trump, quien vio por televisión el debate ante la Corte de Apelaciones, se refirió a ello en un discurso ante la Asociación de Jefes de Alcaldías de Ciudades, diciendo que había «oído cosas que no podía creer», agregando que: «Yo nunca quisiera llamar a una Corte parcializada, de manera

51 Idem.

52 Véase Greg Bensinger y Rachel King, "Tech CEOs Take Stand vs. Trump», The Wall Steet Journal, New York, 7 de febrero de 2017, pág. B1.

53 Véase la información en Adam Liptak, «Justice Department says a Ban on Travel is Vital to Safety», The New York Times, New York, 7 de febrero de 2017, págs. A1, A10. Sobre el rol que asumieron los attorney generals de los estados controlados por los demócratas, véase Alexander Burns, «Democrats Appear to Find a Bulwark Against Trump: Attorney General», The New York Times, New York, 7 de febrero de 2017, págs. A9, A10.

54 Véase un resumen en Devlin Barret, Brent Kendall y Aruna Viswanatha, «Judges Grill Lawyers on Travel Ban», The Wall Steet Journal, New York, 8 de febrero de 2017, pág. A1, A4, y en Adam Liptak, "Judges Question Government Case for Travel ban», The New York Times, New York, 8 de febrero de 2017, págs. A1, A15. 
que no voy a llamar a la Corte parcializada», agregando que no se iba a referir a los «comentarios formulados en la audiencia por un cierto juez». Agregó en su discurso, leyendo parte de la ley que le otorga potestad constitucional para determinar quién puede entrar en el país, que «un mal estudiante de bachillerato podría entender esto; cualquiera podría entender esto», concluyendo que «es realmente increíble para mí que tengamos un caso en una corte que se está tomando tanto tiempo... Digamos simplemente que ellos están interpretando las cosas en forma diferente a probablemente el 100\% de las personas en esta sala» ${ }^{55}$.

En ese ambiente polémico, la Corte de Apelaciones dictó sentencia el 9 de febrero sobre la petición del Gobierno Federal de revocación de la medida cautelar que había acordado el juez de distrito seis días antes, declarando sin lugar la apelación y ratificando la medida cautelar.

\section{LA CONFIRMACIÓN DE LA MEDIDA CAUTELAR DE SUSPENSIÓN DE EFECTOS DE LA ORDEN EJECUTIVA POR PARTE DE LA CORTE DE APELACIONES DEL NOVENO CIRCUITO POR SENTENCIA DE 9 DE FEBRERO DE 2017}

En efecto, la Corte de Apelaciones del Noveno Circuito, con sede en San Francisco, emitió con fecha 9 de febrero de 2017 la sentencia en el caso 17-35105 (Estado de Washington, Estado de Minnesota, Plaintiffs-Appellees v. Donald J. Trump, presidente de los Estados Unidos; U.S. Department Of Homeland Security; Rex W. Tillerson, Secretary of State; John F. Kelly, Secretary of the Department of Homeland Security; United States of America, DefendantsAppellants) sobre la moción de que permaneciera vigente la Orden emitida por la Corte de Distrito del Distrito Oeste de Washington, James L. Robart, juez de distrito ${ }^{56}$.

Para dictar la sentencia y considerar la moción del Gobierno Federal de revocación de la medida cautelar dictada en primera instancia, la Corte de Apelaciones precisó que debía considerar diversos factores:

[...] incluyendo si el Gobierno ha demostrado que tiene probabilidades de tener éxito en el mérito de la apelación, el grado de privación causado por la medida cautelar o su permanencia, y el interés público en el otorgamiento o la

55 Véase Beth Reinhard y Rebecca Balhaus, "Court Nominee Criticizes Trump’s Attacks», The Wall Street Journal, New York, 9 de febrero de 2017, pág. A4.

56 Véase el texto de la sentencia en http://cdn.ca9.uscourts.gov/datastore/opinions/2017/02/09/17-35105.pdf. 
negativa de la solicitud. [Concluyendo, luego del estudio de las evidencias que se presentaron ante la Corte, que:] El Gobierno no ha demostrado que tiene probabilidades de tener éxito en el mérito de la apelación, ni ha demostrado que de no revocarse la medida cautelar podría causar algún daño irreparable, por lo que resolvemos negar la solicitud de emergencia de revocarla.

Para decidir, la Corte de Apelaciones resolvió varios aspectos de orden procesal, sobre su propia competencia, sobre la legitimación activa de los estados demandantes, sobre la posibilidad del control judicial de la propia Orden Ejecutiva, y sobre la incompetencia de funcionarios federales para modificar la Orden Ejecutiva.

\section{LA REAFIRMACIÓN DE SU PROPIA COMPETENCIA POR LA CORTE DE APELACIONES}

En cuanto al tema de la competencia de la Corte de Apelaciones para revisar medidas cautelares (temporary restraining orders), la misma entendió que sí la tenía cuando la medida "posee las cualidades de una preliminary injunction ${ }^{57}$, regla que requiere que el apelante demuestre que la medida cautelar ha sido fuertemente cuestionada en un procedimiento entre partes ante la Corte de Distrito y que la misma está o va a estar en aplicación por un período mayor a los 14 días indicados en las normas de procedimiento federal (Federal Rule of Civil Procedure 65(b)).

En esta materia, la Corte de Apelaciones consideró que en las extraordinarias circunstancias del caso, la orden cautelar de la Corte de Distrito tenía la cualidad de una preliminary injunction apelable, ya que las partes habían impugnado vigorosamente ante la misma, tanto por escrito como oralmente, las bases legales de la orden; no teniendo dicha medida cautelar ninguna fecha de expiración, previéndose en consecuencia que la misma tendría una duración de más de 14 días, particularmente por no haberse fijado alguna audiencia para conocer de la petición de la preliminary injunction.

Por ello, en vista de los argumentos del Gobierno sobre la urgencia de la decisión, la Corte de Apelaciones afirmó su competencia, considerando que el período de la medida cautelar era lo suficientemente largo como para considerar que la misma tenía las cualidades de una «reviewable preliminary injunction» ${ }^{58}$.

57 Cita de la Corte de Apelaciones: Serv. Emps. Int 7 Union v. Nat 7 Union of Healthcare Workers, 598 F.3d 1061. 1067 (9th Cir. 2010).

58 La Corte de Apelaciones aclaró que esta consideración no prejuzgaba sobre la jurisdicción en apelación sobre el mérito. Cita de la Corte: See Nat'l Indus.. Inc. v. Republic Nat'1 Life Ins. Co., 677 F.2d 1258, 1262 (9th Cir. 1982). 


\section{LA DECISIÓN SOBRE LA LEGITIMACIÓN ACTIVA DE LOS ESTADOS PARA DEMANDAR EN ESTE CASO}

El Gobierno Federal, por su parte, alegó que la Corte de Distrito había carecido de materia sobre la cual decidir, porque los estados no tenían la legitimación necesaria para demandar. Sobre ello, la Corte de Apelaciones consideró que tenía la obligación independiente de decidir sobre su jurisdicción ${ }^{59}$, considerando que, en el caso, los estados habían probado suficiente legitimación, al menos en la fase preliminar del procedimiento.

En esta materia, la Corte de Apelaciones consideró que el art. III, sección 2 de la Constitución, permite a los tribunales federales considerar solo "casos» $\mathrm{y}$ "controversias», indicando, como se decidió en el caso Massachusetts v. EPA, 549 U.S. 497, 516 (2007), que «esas palabras reducen la competencia de las cortes federales solo respecto de cuestiones presentadas en un proceso entre partes y en una forma considerada históricamente como capaz de ser resuelta en un proceso judicial $»^{60}$.

La Corte de Apelaciones recordó, además, que «la legitimación es una parte esencial e inmodificable del requisito del caso-o-controversia ${ }^{61}$, agregando que «la esencia de la cuestión sobre legitimación» es que el demandante tenga suficiente interés personal en el resultado de la controversia para asegurar que las partes estarán realmente confrontadas y sus argumentos legales estarán bien afilados ${ }^{62}$.

Para establecer la legitimación conforme al art. III de la Constitución, la Corte consideró que el demandante debía demostrar «que ha sufrido un dańo concreto y particularizado que debe ser actual o inminente, que la lesión sea fácilmente atribuible al demandado, y que sea probable que una decisión favorable pueda compensar la lesión» ${ }^{63}$. Además, consideró la Corte que en virtud de que la legitimación es «una parte indispensable del caso del demandante», debe "estar soportada en la misma forma como cualquier otra materia en la cual el demandante tenga la carga de la prueba, con la manera y grado de evidencia requerido en los estadios sucesivos del litigio ${ }^{64}$.

59 Cita de la Corte de Apelaciones: Arbaugh v. Y\&H Corp., 546 U.S. 500, 514 (2006), and we consider the Government's argument de novo, see, e.g., Hajro v. U.S. Citizenship \& Immigration Servs., 811 F.3d 1086, 1098 (9th Cir. 2016).

60 Cita de la Corte de Apelaciones: Id. quoting Flast v. Cohen, 392 U.S. 83, 95 (1968).

61 Cita de la Corte de Apelaciones: See Lujan v. Defs. of Wildlife, 504 U.S. 555, 560 (1992).

62 Cita de la Corte de Apelaciones: Massachusetts, 549 U.S. at 517, quoting Baker v. Carr, 369 U.S. 186, 204 (1962).

63 Cita de la Corte de Apelaciones: Id. (citing Lujan, 504 U.S. at 560-61).

64 Cita de la Corte de Apelaciones: Id. (citing Lujan, 504 U.S. at 560-61). 
En relación con el caso concreto, en la fase preliminar en la cual se encontraba, la Corte entonces concluyó que los estados podían basarse en los alegatos contenidos en su demanda o en cualquier otra evidencia que sometieron en apoyo de la moción de temporary restraining order (medida cautelar) solicitada a los efectos de lograr esa carga. Con esos alegatos y evidencias, los estados debían «mostrar claramente cada uno de los elementos de su legitimación ${ }^{65}$.

Ahora bien, con base en lo anterior, la Corte de Apelaciones apreció que los estados en el caso "habían argumentado que la Orden Ejecutiva causaba una lesión concreta y particularizada a sus universidades públicas, las cuales las partes no cuestionaron que eran ramas de los Estados conforme a la ley estatal» ${ }^{66}$, haciendo referencia a la situación concreta de algunos profesores y estudiantes nacionales de los siete países afectados, que no podían «viajar para investigar, para colaboración académica, o por razones personales, y sus familias en el extranjero no pueden viajar a visitarlos», agregando que «algunos se han quedado varados fuera del país, impedidos completamente de regresar a la universidad» y que «las escuelas no pueden considerar atractivos a candidatos a estudiantes y no pueden contratar profesores de los siete países afectados, como lo han hecho en el pasado».

Teniendo en cuenta lo anterior, la Corte de Apelaciones consideró, conforme la doctrina de la «third-party standing», que dichas lesiones a las universidades estatales les otorgaba a los estados legitimación para reivindicar los derechos de los estudiantes, académicos y profesores afectados por la Orden Ejecutiva, citando el caso Singleton v. Wulff, 428 U.S. 106, 114-16 (1976), en el cual se explicó que la doctrina "third-party standing» es permitida cuando los intereses de la tercera parte están «indisolublemente unidos a la actividad que el litigante busca perseguir», cuando el litigante está "completamente o muy cerca, como efectivo proponente del derecho» como la tercera parte, o cuando la tercera parte es menos capaz de reivindicar sus propios derechos ${ }^{67}$, y en particular, cuando se ha permitido a las reivindicar los derechos de sus

65 Cita de la Corte de Apelaciones: Townley v. Miller, 722 F.3d 1128, 1133 (9th Cir. 2013). La Corte de Apelaciones agregó en su cita que su decisión en Townley se refirió a una moción para una preliminary injunction, pero los estándares legales aplicables a las temporary restraining orders y a las preliminary injunctions son «sustancialmente idénticas». Stuhlbarg Int'l Sales Co., Inc. v. John D. Brush \& Co., Inc., 240 F.3d 832, 839 n. 7 (9th Cir. 2001).

66 Cita de la Corte de Apelaciones: See, e.g., Hontz v. State, 714 P.2d 1176, 1180 (Wash. 1986) (en banc); Univ. of Minn. v. Raygor, 620 N.W.2d 680, 683 (Minn. 2001).

67 Cita de la Corte de Apelaciones: Craig v. Boren, 429 U.S. 190, 195 (1976); Griswold v. Connecticut, 381 U.S. 479 (1965), y NAACP (National Association for the Advance- 
estudiantes ${ }^{68}{ }_{\eta}$. En sentido similar a lo resuelto en los casos citados por la Corte de Apelaciones, la misma apreció, para admitir la legitimación activa de los Estados impugnantes, que:

[...] los intereses de las universidades de los Estados aquí están en línea con los de sus estudiantes. El éxito educacional de los estudiantes está «indisolublemente unido» en la capacidad de las universidades de enseñarlos Singleton, 428 U.S. at 115. Y la reputación de las universidades depende del éxito de las investigaciones de sus profesores. En consecuencia, como operadores de las universidades estatales, los Estados pueden reivindicar no solo sus propios derechos en lo que estén afectados por la Orden Ejecutiva, sino también pueden reivindicar los derechos de sus estudiantes y de los profesores.

Por lo que concluyó sobre el tema de la legitimación activa, disponiendo que:

[...] los Estados han alegado daños a sus intereses de propiedad trazables hasta la Orden Ejecutiva. La necesaria conexión puede establecerse a lo sumo en dos pasos lógicos: (1) la Orden Ejecutiva impide a los nacionales de los siete países entrar a Washington y Minnesota; (2) como resultado, algunas personas no podrán ingresar a las universidades como profesores, algunas no podrán realizar investigaciones, y a algunas no se les permitirá que regresen si se van. Y no tenemos dificultad en concluir que las lesiones a los Estados serán compensadas si pueden obtener la medida que han solicitado, sobre una declaración de que la Orden Ejecutiva viola la Constitución y un amparo exceptuando su aplicación. El Gobierno no argumentó en otra forma. En consecuencia sostenemos que los Estados tienen legitimación ${ }^{69}$.

ment of Colored People) han sido permitidas para reivindicar los derechos constitucionales de sus miembros, NAACP v. Alabama, 357 U.S. 449 (1958).

68 Citas de la Corte de Apelaciones: Runyon v. McCrary, 427 U.S. 160,175 \& n. 13 (1976); Pierce v. Soc'y of Sisters, 268 U.S. 510, 536 (1925); Parks Sch. of Bus., Inc. v. Symington, 51 F.3d 1480, 1487-88 (9th Cir. 1995), Ohio Ass 'n of Indep. Sch. v. Goff, 92 F.3d 419,422 (6th Cir. 1996).

69 Cita de la Corte de Apelaciones: «Los Estados han reivindicado otros intereses de propiedad y también han presentado una teoría alternativa de legitimación basada en su habilidad de defender los intereses de sus ciudadanos como parens patriae. En virtud de que hemos concluido que los derechos de propiedad de los Estados como operadores de sus universidades públicas son suficientes para apoyar su legitimación, no necesitamos llegar a esos argumentos». 


\section{SOBRE EL PODER DE LAS CORTES FEDERALES PARA CONTROLAR LA CONSTITUCIONALIDAD DE LOS ACTOS EJECUTIVOS}

En el caso, el Gobierno Federal cuestionó la competencia de la Corte de Distrito de suspender la aplicación de la Orden Ejecutiva alegando que el presidente tenía «una autoridad no controlable para suspender la admisión de cualquier clase de extranjeros». Sobre ello, la Corte de Apelaciones destacó que el Gobierno no solamente argumentó que las Cortes deben tener una deferencia sustancial respecto de las decisiones en materia de política de inmigración y de seguridad nacional que corresponden a las ramas políticas del gobierno, lo que es un principio incontrovertido bien fundado en la jurisprudencia de los Estados Unidos ${ }^{70}$, sino que había tomado la posición de afirmar que:

[...] las decisiones del Presidente sobre política de inmigración, particularmente cuando están motivadas en preocupaciones de seguridad nacional, son irrevisables (unreviewable), incluso si dichas acciones potencialmente contravienen derechos y protecciones constitucionales. El Gobierno en efecto argumenta que se viola la separación de poderes cuando la judicatura conoce de una cuestión de constitucionalidad contra acciones ejecutivas como en este caso.

Sobre este alegato del Gobierno, la Corte de Apelaciones expresó que «no hay precedentes para apoyar ese argumento de irrevisabilidad, siendo el mismo más bien contrario a la estructura fundamental de nuestra democracia constitucional», citando el caso Boumediene v. Bush, 553 U.S. 723, 765 (2008), donde se rechazó la idea de que, incluso mediante ley del Congreso, el Congreso y el Ejecutivo puedan llegar a eliminar la jurisdicción de habeas corpus de las cortes federales en relación con los combatientes enemigos, porque las «ramas políticas» del gobierno carecen «del poder de cambiar on or of la Constitución a su voluntad».

Al contrario, la Corte de Apelaciones sostuvo que en el sistema norteamericano, el rol de la rama judicial es interpretar la ley, que es un deber que en algunas ocasiones requiere «la resolución de litigios cuestionando la autoridad constitucional de algunas de las tres ramas» ${ }^{71}$ y por ello, dijo la Corte

70 Cita de la Corte de Apelaciones: See, e.g., Cardenas v. United States. 826 F.3d 1164, 1169 (9th Cir. 2016) (reconociendo que «el poder de expulsar o excluir a extranjeros es una atribución soberana fundamental ejercida por los departamentos políticos del Gobierno ampliamente inmune a control judicial» — citando Fiallo v. Bell, 430 U.S. 787, 792 (1977)—); véase también Holder v. Humanitarian Law Project, 561 U.S. 1, 33-34 (2010).

71 Cita de la Corte de Apelaciones: Zivotofsky ex rel. Zivotofsky v. Clinton, 566 U.S. 189, 196 (2012) (quoting INS v. Chadha, 462 U.S. 919, 943 (1983)). 
de Apelaciones, que sus jueces precisamente estaban llamados a cumplir este deber en este caso.

Así, consideró la Corte que si bien la jurisprudencia desde hace tiempo había aconsejado deferencia respecto de las ramas políticas del gobierno en materia de inmigración y seguridad nacional, en ningún caso, ni la Corte Suprema ni la Corte han sostenido que las cortes carecen de autoridad para revisar las acciones ejecutivas en esas áreas, para verificar que cumplen con la Constitución.

Al contrario, constató la Corte de Apelaciones, que la Corte Suprema repetida y explícitamente ha rechazado toda noción de que las ramas políticas tienen autoridad irrevisable en materia de inmigración o que no están sujetas a la Constitución cuando definen su política en ese contexto, citando el caso Zadvydas v. Davis, 533 U.S. 678, 695 (2001), en el cual se enfatizó que ese poder de las ramas políticas en materia de inmigración, «está sujeto a importantes limitaciones constitucionales", el caso Chadha, 462 U.S. at $940-$ 41, en el cual se rechazó el argumento de que el Congreso tenga «autoridad irrevisable en materia de regulación de extranjeros» y se afirmó que las Cortes pueden revisar «si el Congreso ha seguido un medio constitucional permitido para implementar tal poder ${ }^{72}$. En otras palabras, dijo la Corte de Apelaciones citando el caso American-Arab Anti-Discrimination Comm. v. Reno, 70 F.3d 1045, 1056 (9th Cir. 1995), «nuestra Corte ha dicho claramente que aun cuando algunas clasificaciones de extranjeros están estrechamente conectadas con materias de política exterior y seguridad nacional», las Cortes "pueden y deben revisar argumentos de política exterior que con frecuencia se ofrecen

72 Cita de la Corte de Apelaciones: véase también Galvan v. Press, 347 U.S. 522, 530 (1954), reafirmando el amplio poder del Congreso en materia de inmigración, pero observando que «en la aplicación de esas políticas, la Rama Ejecutiva del Gobierno debe respetar las salvaguardas procedimentales del debido proceso»; el caso Yamataya v. Fisher, 189 U.S. 86,100-01 (1903), reafirmando en el contexto de decidir un cuestionamiento constitucional a una política de inmigración, que «esta Corte nunca ha sostenido, ni debe entenderse ahora que pueda sostener, que funcionarios de la administración puedan ignorar los principios fundamentales inherentes al due process of law, tal como se entendió al momento de la adopción de la Constitución, cuando ejecuten las previsiones de leyes que se refieran a la libertad de las personas», y el caso Chae Chan Ping v. United States, 130 U.S. 581, 604 (1889), en el cual se sostuvo que «el poder de declarar la guerra, hacer tratados [...] o admitir personas de otras naciones a la ciudadanía, son todos poderes soberanos, restringidos en su ejercicio solo por la Constitución misma y las consideraciones de políticas públicas y justicia que controlan, más menos, la conducta de todas las naciones civilizadas». 
como justificativos de acciones legislativas y ejecutivas cuando hay derechos constitucionales involucrados».

En definitiva, la Corte de Apelaciones concluyó indicando que si bien era consciente de la deferencia debida a las ramas políticas del gobierno, particularmente apropiada respecto de asuntos de seguridad nacional y relaciones exteriores respecto de lo cual poseen más capacidad relativa institucional, acceso a la información y experticia ${ }^{73}$, sin embargo, «las cortes no son impotentes para revisar las "acciones" de las ramas políticas respecto de materias de seguridad nacional ${ }^{74}$. Es decir, como la Corte Suprema ha indicado claramente, «la autoridad y experticia del Gobierno en tales materias no elimina la propia obligación de la Corte de asegurar la protección que la Constitución otorga a los individuos» incluso en tiempos de guerra ${ }^{75}$, citando al efecto el caso United States v. Robel, 389 U.S. 258, 264 (1967), en el cual se sostuvo que «la defensa nacional no puede ser considerada un fin en sí misma, justificando cualquier ejercicio del poder de legislar para lograr tal objetivo... Sería en efecto irónico si, en el nombre de la defensa nacional, pudiéramos sancionar la subversión de una de esas libertades [...] que hacen que valga la pena la defensa de la nación», y el caso Zemel v. Rusk, 381 U.S. 1, 17 (1965), en el cual se sostuvo que «simplemente porque una ley se refiera a las relaciones exteriores, [ello no significa que] pueda otorgar al Ejecutivo una total e irrestricta libertad de escogencia ${ }^{76}$.

En fin, dijo la Corte de Apelaciones, citando a varios jueces de la Corte Suprema en el caso Hamdi v. Rumsfeld, 542 U.S. 507 (2004): «En cualquier poder que la Constitución de los Estados Unidos prevea para el Ejecutivo en sus relaciones con otras naciones o con organizaciones enemigas en tiempo de conflicto, cuando las libertades individuales estén envueltas, lo más seguro es que se prevea un rol para todas las tres ramas [del gobierno]» ${ }^{77}$, concluyendo su sentencia afirmando en materia de control de constitucionalidad de la acción ejecutiva, que:

[...] a pesar de que las cortes deban considerable deferencia a las determinaciones de política en materia de inmigración y de seguridad nacional, está fuera de

73 Cita de la Corte de Apelaciones: Humanitarian Law Project, 561 U.S. at 33-34.

74 Cita de la Corte de Apelaciones: Alperin v. Vatican Bank, 410 F.3d 532, 559 n. 17 (9th Cir. 2005).

75 Cita de la Corte de Apelaciones: Humanitarian Law Project, 561 U.S. at 34, quoting id. at 61 (Breyer, J., dissenting).

76 Otras citas de la Corte de Apelaciones: Boumediene, 553 U.S. 723; Aptheker v. Sec'y of State, 378 U.S. 500 (1964); Ex parte Endo, 323 U.S. 283 (1944).

77 Cita de la Corte de Apelaciones: Id. at 536 (plurality opinion). 
toda duda que la judicatura federal retiene la autoridad para decidir sobre los cuestionamientos constitucionales que se formulen en relación con las acciones ejecutivas.

\section{SOBRE LA INCOMPETENCIA DE FUNCIONARIOS FEDERALES SUBALTERNOS PARA MODIFICAR LA ORDEN EJECUTIVA}

Otra cuestión planteada con motivo del desarrollo del proceso y decidida por la Corte de Apelaciones fue la relativa a la competencia para poder modificar la Orden Ejecutiva que había sido impugnada. Sobre ello, el Gobierno presentó en juicio, junto con sus argumentos, una copia de una "Guía de aplicación» relativa a la Orden Ejecutiva que fue emitida siete días después de su publicación, firmada por el consultor jurídico de la Casa Blanca, Donald F. McGahan II, en la cual se indicaba que las secciones 3.c y 3.e de la Orden no se aplicarían a los residentes permanentes. Sobre esta supuesta modificación de la Orden Ejecutiva, la Corte de Apelaciones consideró que en el estadio en el que se encontraba el procedimiento, no podía confiar en el argumento del Gobierno de que la Orden Ejecutiva supuestamente ya no se aplicaba a los residentes permanentes, destacando que:

[...] el Gobierno no había ofrecido ningún apoyo legal (authority) estableciendo que el Consultor Jurídico de la Casa Blanca tiene el poder para emitir una orden de enmienda que sustituya la Orden Ejecutiva firmada por el Presidente que ha sido cuestionada por los Estados, siendo ello muy improbable que pueda ocurrir.

Se trataba, efectivamente, de una violación del clásico principio de la jerarquía de las normas, tan conocido en los ordenamientos jurídicos iberoamericanos, según el cual «ningún acto administrativo podrá violar lo establecido en otro de superior jerarquía», como por ejemplo así lo indica el artículo 13 de la Ley de Procedimientos Administrativos de Venezuela, siguiendo en general la orientación de la inicial Ley de Procedimientos Administrativos de España emitida en los años cincuenta ${ }^{78}$.

Pero la Corte de Apelaciones fue más allá, e indicó que, en este caso, el Gobierno tampoco había establecido que:

78 Véanse, por todos, Allan R. Brewer-Carías (1990), Principios del procedimiento administrativo (Prólogo de Eduardo García de Enterría), Madrid: Editorial Civitas, y (2003), Principios del procedimiento administrativo en América Latina, Bogotá: Universidad del Rosario, Colegio Mayor de Nuestra Señora del Rosario, Editorial Legis, pág. 24. 
[...] la interpretación del Consultor Jurídico de la Casa Blanca era vinculante respecto de todos los funcionarios responsables de la rama ejecutiva para aplicar la Orden Ejecutiva. El Consultor Jurídico de la Casa Blanca no es el Presidente, y no se conoce que esté en la cadena de mando de algún Departamento del Ejecutivo. Más aún, en vista del cambio de interpretación del Gobierno de la Orden Ejecutiva, no podemos decir que la actual interpretación del Consultor de la Casa Blanca, incluso si fuera autoritativa y vinculante, persistiría una vez transcurrida la fase inmediata de este procedimiento. En esta decisión, en consecuencia, no podemos concluir que el Gobierno ha demostrado que sea "absolutamente claro que la alegada conducta errada no pueda razonablemente esperarse que se repita"79.

La esencia del razonamiento, en todo caso, aparte de las consideraciones procesales, se basó en otro de los principios universales de la conducta de los funcionarios de la Administración pública, y es el principio de la competencia, que siempre tiene que ser establecida en texto legal expreso ${ }^{80}$.

\section{SOBRE EL ÁMBITO DE APLICACIÓN DE LA MEDIDA CAUTELAR ADOPTADA POR EL JUEZ DE DISTRITO, CON ÁMBITO DE NIVEL NACIONAL}

Otra cuestión considerada y resuelta por la Corte de Apelaciones fue el cuestionamiento efectuado por el Gobierno respecto del ámbito de aplicación de la medida cautelar apelada que había emitido el juez de distrito. El Gobierno consideró que aun si los Estados podían mostrar en juicio que tendrían probabilidades de triunfar, el juez de distrito había errado al haber extendido los efectos de la temporary restraining order a extranjeros que no eran residentes permanentes, y además, con efectos a nivel nacional, más allá del territorio de los estados de Washington y Minnesota, que fueron los demandantes.

El alegato fue desestimado por la Corte de Apelaciones basándose en los siguientes argumentos. Primero, en cuanto al alegato del Gobierno de limitar la medida cautelar solo a los residentes permanentes, y a la categoría adicional que se incluyó en el mencionado memorándum del consultor jurídico de la Casa Blanca referida a «los extranjeros que habían sido previamente admitidos

79 Cita de la Corte de Apelaciones; Friends of the Earth, Inc., v. Laidlaw Envtl. Servs., Inc., 528 U.S. 167, 189 (2000) (emphasis added).

80 Véanse, igualmente por todos, Allan R. Brewer-Carías (1990), Principios del procedimiento administrativo (prólogo de Eduardo García de Enterría), Madrid: Editorial Civitas, y (2003), Principios del procedimiento administrativo en América Latina, Bogotá: Universidad del Rosario, Colegio Mayor de Nuestra Señora del Rosario, Editorial Legis, págs. 186 ss. 
en los Estados Unidos, que estaban temporalmente fuera y ahora desean regresar en el futuro a los Estados Unidos», la Corte consideró de entrada que esas modificaciones omitían el caso de los extranjeros que están en los Estados Unidos en forma ilegal, y que, sin embargo, también tienen derechos del debido proceso ${ }^{81}$, y el caso de reclamos de ciudadanos que tienen interés en viajar al extranjero en una específica capacidad de no ciudadano ${ }^{82}$.

Segundo, la Corte de Apelaciones también desestimó la petición del Gobierno Federal de que se limitara geográficamente el ámbito de aplicación de la medida cautelar, destacando que el juez de distrito había argumentado correctamente que una fragmentación de la política inmigratoria en el territorio del país sería contraria al requerimiento constitucional y legal de la aplicación uniforme de la ley y de la política en materia inmigratoria ${ }^{83}$. Si bien en esta materia la Corte de Apelaciones no consideró que en el estado en el cual se encontraba el procedimiento era necesario llegar a esa misma posición, estimó que el Gobierno no había establecido que el punto de vista contrario podría prevalecer. Consideró la Corte que, incluso, aun si considerase que la limitación al ámbito geográfico de la injunction fuera deseable, el Gobierno no había propuesto ninguna forma alternativa viable para la medida cautelar, que tomase en cuenta los múltiples puertos de entrada a la nación y el sistema interconectado de tránsito que pueda proteger los derechos propios de los Estados demandantes, solo aplicando la medida a las fronteras de los mismos.

Pero, agregó la Corte, incluso si se pudiera considerar que la temporary restraining order pudiera ser excesiva en algunos aspectos ${ }^{84}$, no era el rol de la Corte el tratar de reescribir la Orden Ejecutiva, considerando que eran las ramas políticas del gobierno las que estaban mucho mejor equipadas para adoptar las distinciones apropiadas, por lo que consideró que, por ahora, era suficiente concluir que el Gobierno había fracasado en establecer que tenía probabilidades de triunfar en sus argumentos sobre debido proceso formulados en la apelación.

Con base en todos los argumentos antes analizados, la Corte de Apelaciones en definitiva desestimó los alegatos del Gobierno, negó la apelación

81 Cita de la Corte de Apelaciones Zadvydas, 533 U.S. at 693.

82 Cita de la Corte de Apelaciones: Din, 135 S. Ct. at 2139 (Kennedy, J., concurring in judgment); id. at 2142 (Breyer, J., dissenting).

83 Cita de la Corte de Apelaciones: Texas v. United States, 809 F.3d 134, 187-88 (5th Cir. 2015), aff'd by an equally divided Court, 136 S. Ct. 2271 (2016).

84 Cita de la Corte de Apelaciones: United States v. Nat 1 Treasury Emps. Union, 513 U.S. 454, 479 (1995) (declining to rewrite a statute to eliminate constitutional defects); cf Aptheker v. Sec'y of State, 378 U.S. 500, 516 (1964) (invalidating a restriction on freedom of travel despite the existence of constitutional applications). 
que se había formulado contra la medida cautelar de protección o amparo que había dictado unos días antes el juez de distrito Robart, rechazando la moción de emergencia formulada para revocarla, ratificando en consecuencia la suspensión de efectos de la Orden Ejecutiva impugnada a nivel nacional.

Para ello, en definitiva, la Corte de Apelaciones consideró que el Gobierno no había probado en forma alguna que la revocación de la medida era necesaria para evitar algún perjuicio irreparable, expresando que aun cuando podía coincidir con que «el interés del Gobierno en combatir el terrorismo es un objetivo urgente del más alto orden ${ }^{85}$, en el caso, el Gobierno no había hecho nada más sino reiterar tal hecho, de manera que a pesar de los requerimientos del juez de distrito y de la propia Corte de que explicara la urgente necesidad de restablecer los efectos de la Orden Ejecutiva de manera inmediata, el Gobierno no había sometido evidencia alguna para contradecir los argumentos de los Estados, de que con la orden del juez de distrito lo que se había logrado era solo devolver a la nación temporalmente a la posición que había ocupado en muchos de los años precedentes.

La Corte reiteró además en su sentencia que el Gobierno no aportó evidencia alguna de que algún extranjero de los países nombrados en la Orden Ejecutiva hubiera perpetrado algún ataque terrorista en los Estados Unidos, y antes que presentar evidencia para explicar la necesidad de la Orden Ejecutiva, el Gobierno lo que había hecho fue adoptar la posición de que las Cortes no podían revisar sus decisiones en forma alguna, con lo cual la Corte de Apelaciones no estuvo de acuerdo, y rechazó, como se analizó anteriormente.

\section{APRECIACIÓN FINAL}

Una vez conocida la decisión de la Corte de Apelaciones del Noveno Circuito en San Francisco, de nuevo se produjo una inusitada reacción pública por parte del presidente de Estados Unidos, quien calificó la decisión como una «decisión política» ${ }^{86} \mathrm{y}$ "vergonzosa» ${ }^{87}$, expresando en general que «nuestro sistema legal está roto» ${ }^{88} \mathrm{y}$, en forma amenazante, que «los veremos en la Corte.

85 Cita de la Corte de Apelaciones: Holder v. Humanitarian Law Project, 561 U.S. 1, 28 (2010).

86 Véase Adam Liptak, "Judges Refuse to Reinstate Travel ban», The New York Times, New York, 10 de febrero de 2017, pág. A1.

87 Véase Rebecca Ballhaus y Carol E. Lee, «Trump Eyes New Order on Travel», The Wall Street Journal, New York, 11 de febrero de 2017, pág. A1.

88 Véase Julie Hirschfeld Davis, "Misleading New Claim On a Rush of Refugees», The New York Times, New York, 12 de febrero de 2017, pág. 15. 
La seguridad de nuestra nación está en peligro" ${ }^{89}$. No precisó, sin embargo, en cuál Corte y a quién vería, siendo improbable hacia el futuro que el Gobierno efectivamente recurriera en justicia el asunto ante la Corte Suprema ${ }^{90}$.

Y ello quedó confirmado con la comunicación formulada por el Departamento de Justicia ante la Corte de Apelaciones el 17 de febrero de 2017 en el sentido de que el Gobierno, en lugar de continuar con el litigio, pensaba reformular la Orden Ejecutiva y, por tanto, no buscaría que se realizara ninguna audiencia adicional en el juicio, de manera que la Corte no tenía razones adicionales para considerar la versión que había sido objeto de litigio ${ }^{91}$. Quedó evidenciada, así, la efectividad de la justicia cautelar de amparo como mecanismo adecuado para la protección inmediata de derechos fundamentales.

En todo caso, la justicia cautelar no concluyó su operación con las decisiones del juez de distrito de Washington y de la Corte de Apelaciones del Noveno Circuito de San Francisco, sino que continuó manifestándose en otras decisiones de otras Cortes federales de distrito, como la adoptada en Alexandria, en el estado de Virginia, el 13 de febrero de 2017, donde la juez Leonie Brinkema, del Distrito Este de dicho estado, dictó sentencia en el caso Tareq Aqel Momammed Aziz et al. vs. Donald Trump, adoptando una preliminary injunction contra la Orden Ejecutiva, pero limitada, suspendiendo sus efectos solo respecto de los residentes del estado de Virginia ${ }^{92}$.

89 Véase Devlin Barrett y Brent Kendall, «Court Deals Fresh Blow to Trump», The Wall Street Journal, New York, 10 de febrero de 2017, pág. A1u.

90 Véase, por ejemplo, el comentario de Adam Liptak, "After the Ruling, and the Tweet, What Come Next?», The New York Times, New York, 11 de febrero de 2017, pág. A8.

91 Lo expresado ante la Corte de Apelaciones por el Departamento de Justicia fue que «el Presidente tiene la intención en un futuro cercano de rescindir la Orden y reemplazarla con una nueva Orden Ejecutiva sustancialmente revisada, para eliminar lo que la Corte de Apelaciones erróneamente pensó que causaba preocupaciones constitucionales. Procediendo en esta forma, el Presidente despejará el camino para la protección inmediata del país, en lugar de continuar un potentially time-consuming litigation». El Departamento de Justicia solicitó entonces a la Corte esperar la nueva Orden anunciada para la siguiente semana para dejar sin efecto su decisión, lo que en todo caso quedó a juicio de la misma. Véase la información en Adam Lipak, "Justice Dept. Drops Travel ban Case, but Says a New Order Is Coming», The New York Times, New York, 17 de febrero de 2017, pág. A16, y en Brent Kendall y Laura Meckler, «Revamp of Migration Order Looms», The Wall Street Journal, New York, 17 de febrero de 2017, pág. A4.

92 La juez había dictado una temporary restraining order el 8 de febrero de 2017 en relación con residentes en el estado de Virginia afectados en el aeropuerto de Dulles, cerca de Washington (véase la decisión en https://www.justice4all.org/wp-content/ uploads/2017/01/TRO-order-signed.pdf), habiendo posteriormente dictado el 13 de 
Lo anterior solo muestra las vicisitudes iniciales de un litigio iniciado en el marco de la justicia constitucional en los Estados Unidos por unos estados de la Unión norteamericana, los estados de Washington y de Minnesota, contra una Orden Ejecutiva dictada por el presidente de los Estados Unidos el 27 de enero de 2017, en una materia tan sensible en ese país como es el régimen de la inmigración y de los inmigrantes que por los argumentos y documentos que se analizaron en las sentencias, aparentemente fue adoptada a la carrera, y sin las necesarias consultas previas con los departamentos del Gobierno involucrados en su implementación y aplicación, lo que, en definitiva, ocasionó la decisión de sustituir y reescribir la Orden ${ }^{93}$.

En todo caso, resulta alarmante para cualquier estudioso del derecho público constatar cómo en el caso, además, por los problemas que originó la aplicación de la Orden Ejecutiva, a los pocos días el Gobierno pretendió modificarla, pero no como correspondía, que era mediante una modificación por parte del presidente o mediante la emisión por este de una nueva Orden Ejecutiva, sino como lo advirtió la Corte de Apelaciones del Noveno Circuito, por un funcionario incompetente como era el consultor jurídico de la Casa Blanca, que incluso no forma parte de ninguno de los departamentos del Gobierno encargados de aplicarla.

No es de extrańar, por tanto, que el proceso iniciado por dos de los estados de la Unión contra la Orden Ejecutiva, en su fase más preliminar, hubiera

febrero de 2017 una preliminary injunction (véase en http://www.leagle.com/decision/ In\%20FDCO\%2020170214D23/AZIZ\%20v.\%20TRUMP). Lo más importante de esta decisión, al contrario de la sentencia dictada por el juez de distrito del estado de Washington, es que la juez sí apreció la denuncia de la «Muslim ban», considerada por el juez de Washington que tocaba intereses sensitivos, concluyendo, como lo comentó el profesor Eric Posner de la Chicago University Law School, que «el Presidente actuó con ánimo contra los Musulmanes cuando dictó la prohibición de viajar, para lo cual la Corte, entre otras, apreció como evidencia dañosa, las afirmaciones [de Trump] durante la campaña presidencial llamando a la prohibición, musulmana que todavía está en la web» y las entrevistas que le hicieron a Trump. Véase Eric Posner, «Judges v. President: We All Lose?», The New York Times, New York, 16 de febrero de 2017, pág. A27.

93 Ello lo confirmó el propio presidente Donald J. Trump en la muy publicitada rueda de prensa que dio el 16 de febrero de 2017, en la cual, al argumentar que el Gobierno había caído en una bad Court y que lo que habían obtenido había sido una very bad decision, emitiría una nueva orden. Véase en Reuters, "Donald Trump to replace travel ban order for seven Muslim-majority countries "in near future"», The Telegraph, 16 de febrero de 2017, en http://www.telegraph.co.uk/news/2017/02/16/donald-trumpreplace-travel-ban-order-seven-muslim-majority/. 
terminado con una medida de amparo cautelar (temporary restraining order) en protección de los derechos de los residentes no solo de los estados demandantes y de sus derechos de propiedad, sino con ámbito general respecto de todas las personas afectadas, y que fue dictada con carácter de preliminary injunction (amparo), como fue la decisión adoptada por el juez de distrito del Distrito Oeste del estado de Washington el 3 de febrero de 2017, ratificada por la Corte de Apelaciones del Noveno Circuito en San Francisco ${ }^{94}$ de 9 de febrero de 2017, que son las que hemos comentado en las líneas precedentes.

New York, 17 de febrero de 2017

94 Véanse los comentarios generales a las sentencias en el editorial «Trump’s Judicial Debacle», The New York Times, New York, 11 de febrero de 2017, pág. A12, y en David B. Rivkin Jr. y Lee A. Casey, «The Ninth Circuit Ignores Precedent and Treatens National Security», The Wall Street Journal, New York, 11 de febrero de 2017, pág. A13. 